\title{
Tribological Properties of Thermo-Reversible Gel-Lubricants Containing Solid Lubricants
}

\author{
Kazumi Sakai ${ }^{*}$ Yuji Shitara, Kazutoshi Takahashi, Kouichi Yoshida and Takashi Kaimai \\ Lubricants Research \& Development Center, Japan Energy Corporation \\ 3-17-35 Niizo-Minami, Toda-shi, Saitama 335-8502, Japan \\ *Corresponding author: ka.sakai@j-energy.co.jp
}

( Manuscript received 20 November 2009; accepted 16 December 2009; published 31 January 2011 )

(Presented at the World Tribology Congress 2009, Kyoto, 6-11 September, 2009)

\begin{abstract}
Previously, we have reported tribological characteristics of a new unique Thermo-Reversible Gel-Lubricants (TR Gel-Lube), which consists of base fluids and gel agent. TR Gel-Lube has low friction property compared with conventional greases under mild lubricating conditions. However, under severe lubricating condition, extreme pressure (EP) property must be improved by some EP additives. In this study, addition of solid lubricants was investigated. Tribological properties were examined by some tribometers and various enhancements by Molybdenum disulfide, Melamine Cyanuric Acid and Boron Nitrides were observed. Mechanisms of the lubricity improvements were proposed by results of some chemical/physical analyses.
\end{abstract}

Keywords: tribology, TR Gel-Lube, solid lubricant, low friction coefficient, extreme pressure property

\section{Introduction}

In recent years, remarkable developments of industrial machines have been made. Lubricating greases are used for those machines and required various kind of performances such as long life, energy saving, anti-wear property ${ }^{1}$. High performance greases containing synthetic base fluids and/or solid lubricants have been developed to fulfill high-level demands. Even such greases have a potential problem resulting from thickeners. It is known as the oil starvation leading to lubricating troubles.

As one of solutions to these matter, we have proposed an unique Thermo-Reversible Gel-Lubricants, which consists of base fluids and gel agents, instead of thickeners $^{2)}$. The most important characteristic is its reversible change of physical state, as shown in Fig. 1. The physical state of TR Gel-Lube changes from the gel state to the liquid state by heating. On the contrary, TR Gel-Lube in the liquid state changes to the gel state by cooling. This physical state change of TR Gel-Lube is thermally reversible, differs from greases.

The mechanism of thermo-reversible property is shown in Fig. 2. The gel agent has polar group and lipophilic group. TR Gel-Lube looks like grease in ambient temperature. In this gel state, TR Gel-Lube might form three-dimensional network of base fluids and gel agent, influenced by hydrogen bonds among gel

agents and van der Waals' force between base fluid and gel agents. These chemical bonds are easily broken by thermal energy and/or mechanical shearing force. So TR Gel-Lube changes from the gel state to the liquid state by heating up to the melting point of its gel agent. The temperature of physical state change depends on the molecule structure of gel agent. In this study, aliphatic amide compounds were used as gel agent.

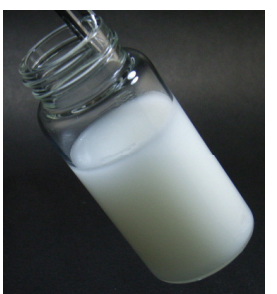

Gel

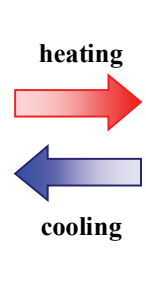

Fig. 1 Physical state change of TR Gel-Lube

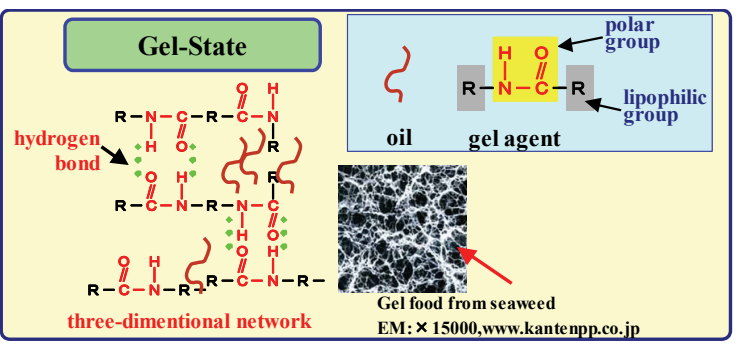

Fig. 2 Structure model of TR Gel-Lube

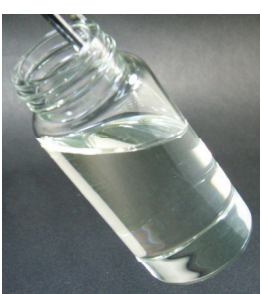

Sol 
TR Gel-Lube has good tribological properties, such as low friction coefficient, long fatigue life, strong adhesive power, water resistance, etc. compared with conventional greases $^{2-4)}$. For instance, low friction property was measured by SODA-type pendulum tester. The results of the test under boundary lubrication are shown in Fig. 3. The contact pressure was $0.97 \mathrm{GPa}$. The friction coefficient of TR Gel-Lube was 30\% lower than that of base fluid and conventional greases. The gel agent significantly decreased the friction resistance.

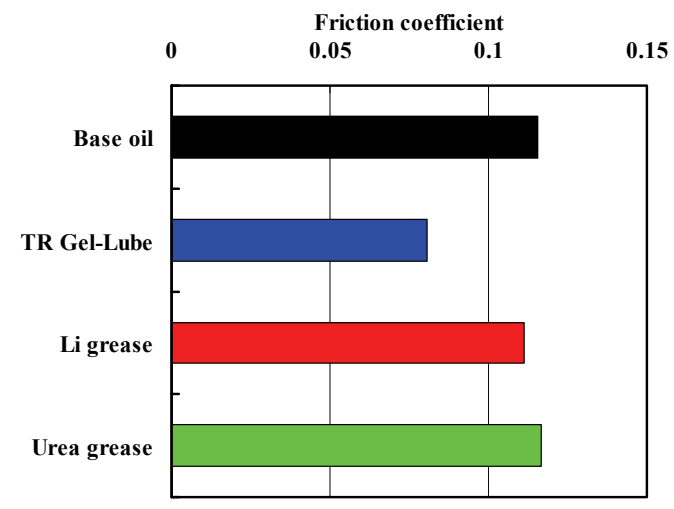

Fig. 3 Friction coefficient by pendulum test ${ }^{2)}$

Concerning the mechanism of low friction property of TR Gel-Lubes, gel agents play an important role in lubricating properties according to observation of EHL behavior $^{3)}$. As shown in Fig. 4, Gel agents can easily and strongly adsorb on metal surfaces with their own polar groups like oiliness agents.

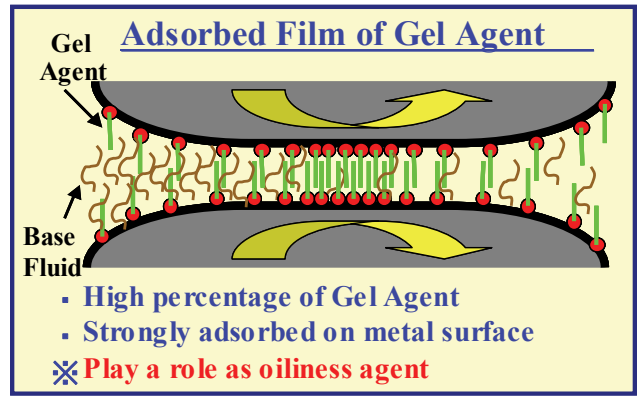

Fig. 4 Mechanism of TR Gel-Lube ${ }^{3)}$

On the other hand, for the application under severe lubricating conditions, TR Gel-Lube is required to improve EP property by some EP additives. Because gel agents behave as oiliness agent as described above, they can't endure under severe lubricating condition like conventional oiliness agents. However, an easy choice of EP additive might have harmful effects to machinery components and workers, such as metal corrosion and bad odor caused by sulfur compounds.

As to lubricating greases, solid lubricants have been used to improve EP property because there is no necessity to concern deposition of solid lubricants comparing with oil lubricants. Molybdenum disulfide
$\left(\mathrm{MoS}_{2}\right)$ is the most popular solid lubricant used in lubricating grease $\mathrm{s}^{5}$. Other solid lubricants are polytetrafluoroethylene (PTFE), melamine cyanuric acid adduct (MCA), graphite, etc. Those solid lubricants have been used for improving EP property, friction property, anti-wear performance and reducing noise ${ }^{6-8)}$. Synergy effects of solid lubricants have been reported ${ }^{9)}$. The above effects of solid lubricants are expected not only for greases but also for TR Gel-Lubes.

In this study, the addition of solid lubricants to TR Gel-Lube was performed to improve mainly EP property. Two types of solid lubricants were investigated. One type is known as solid lubricants that have the cleavage property and reduce the shear resistance, such as $\mathrm{MoS}_{2}$, MCA and Boron Nitrides (BN). The other type is nanoparticles that have fill in the roughness of the friction surfaces and smooth them, such as zinc oxides $(\mathrm{ZnO})$. The tribological properties were examined by FALEX (pin on block) testing machine, etc. The improvement of extreme pressure property and anti-wear property was observed by the addition of solid lubricants to TR Gel-Lube. The mechanisms of the improvement of lubricity were proposed by results of some physical/chemical analysis.

\section{Experimental}

\subsection{Solid lubricants}

As mentioned above, four kind of solid lubricants were investigated. Lubricants' properties are shown in Table $1 . \mathrm{MoS}_{2}$ is well known as solid lubricant that has cleavage property. MCA has layer structure like $\mathrm{MoS}_{2}$ and easily cleaves. BN has hexagonal structure like graphite and works as solid lubricants. $\mathrm{ZnO}$ is nanosized particles without cleavage property.

Table 1 Property of solid lubricants

\begin{tabular}{l|c|c|c|c}
\hline & $\mathrm{MoS}_{2}$ & $\mathrm{MCA}$ & $\mathrm{BN}$ & $\mathrm{ZnO}$ \\
\hline Particle size & $1 \mu \mathrm{m}$ & $0.5 \mu \mathrm{m}$ & $2 \mu \mathrm{m}$ & $34 \mathrm{~nm}$ \\
\hline $\begin{array}{l}\text { Mohs } \\
\text { hardness }\end{array}$ & 1 & - & 2 & 4.2 \\
\hline $\begin{array}{l}\text { Resistance to } \\
\text { temperature } \\
\text { (in air) }\end{array}$ & $350^{\circ} \mathrm{C}$ & $300^{\circ} \mathrm{C}$ & $700{ }^{\circ} \mathrm{C}$ & $\begin{array}{c}1790 \\
{ }^{\circ} \mathrm{C}\end{array}$ \\
\hline
\end{tabular}

\subsection{Samples}

In this study, standard TR Gel-Lube consists of $10 \%$ of aliphatic-bis-amide compounds, $2 \%$ of anti-wear additive (TCP) and poly- $\alpha$-olefin (PAO VG400). Some TR Gel-Lubes contain solid lubricants (Table 2). Conventional lithium greases in similar formulation except thickener were prepared for comparing with TR Gel-Lubes(Table 3).

\subsection{Tribological tests and analyses}

Lubricating properties were measured by pin-on-block type FALEX tester, ball-on-plate type SRV tester and ball-on-plate type BOD tester (Fig. 5). These test 
Table 2 Formulation of samples (TR Gel-Lubes)

\begin{tabular}{l|c|c|c|c|c}
\hline & $\begin{array}{c}\text { TR } \\
\text { Gel-N }\end{array}$ & $\begin{array}{c}\text { TR } \\
\text { Gel-M }\end{array}$ & $\begin{array}{c}\text { TR } \\
\text { Gel-C }\end{array}$ & $\begin{array}{c}\text { TR } \\
\text { Gel-B }\end{array}$ & $\begin{array}{c}\text { TR } \\
\text { Gel-Z }\end{array}$ \\
\hline PAO & $88 \%$ & $83 \%$ & $83 \%$ & $83 \%$ & $83 \%$ \\
\hline Gel agent & $10 \%$ & $10 \%$ & $10 \%$ & $10 \%$ & $10 \%$ \\
\hline $\begin{array}{l}\text { Anti-wear } \\
\text { add. }\end{array}$ & $2 \%$ & $2 \%$ & $2 \%$ & $2 \%$ & $2 \%$ \\
\hline $\mathrm{MoS}_{2}$ & - & $5 \%$ & - & - & - \\
\hline $\mathrm{MCA}$ & - & - & $5 \%$ & - & - \\
\hline $\mathrm{BN}$ & - & - & - & $5 \%$ & - \\
\hline $\mathrm{ZnO}$ & - & - & - & - & $5 \%$ \\
\hline
\end{tabular}

Table 3 Formulation of samples (Lithium greases)

\begin{tabular}{l|c|c|c|c|c}
\hline & Li-N & Li-M & Li-C & Li-B & Li-Z \\
\hline PAO & $90 \%$ & $85 \%$ & $85 \%$ & $85 \%$ & $85 \%$ \\
\hline Li stearate & $8 \%$ & $8 \%$ & $8 \%$ & $8 \%$ & $8 \%$ \\
\hline $\begin{array}{l}\text { Anti-wear } \\
\text { add. }\end{array}$ & $2 \%$ & $2 \%$ & $2 \%$ & $2 \%$ & $2 \%$ \\
\hline $\mathrm{MoS}_{2}$ & - & $5 \%$ & - & - & - \\
\hline $\mathrm{MCA}$ & - & - & $5 \%$ & - & - \\
\hline $\mathrm{BN}$ & - & - & - & $5 \%$ & - \\
\hline $\mathrm{ZnO}$ & - & - & - & - & $5 \%$
\end{tabular}

PAO: poly- $\alpha$-olefin base fluid [VG400]

Gel agent: Aliphatic-bis-amide [melting point: $150{ }^{\circ} \mathrm{C}$ ]

Anti-wear add.: tricresyl phosphate [TCP]

conditions are summarized in Tables 4 and 5 .

Thermal stability of TR Gel-lubes was observed by TG, thermo gravimetric analysis. Weight reductions of TR Gel-Lubes were measured with temperature increasing. Rate of temperature increase is $10^{\circ} \mathrm{C} / \mathrm{min}$. up to $1000^{\circ} \mathrm{C}$ under air flowing condition $(100 \mathrm{~mL} / \mathrm{min})$.

Friction surfaces of rubbed SRV specimens were analyzed by EPMA, Raman and FT-IR micro spectroscopy to obtain chemical information of solid lubricants.

Table 4 Test conditions of FALEX and SRV

\begin{tabular}{l|c|c}
\hline & FALEX & SRV \\
\hline Specimen & $\begin{array}{c}\text { Pin, SAE 3135 } \\
\text { Block, AISI C1137 }\end{array}$ & $\begin{array}{c}\text { Ball, SUJ-2, } \varphi 10 \\
\text { Disk, SUJ-2 }\end{array}$ \\
\hline Load & up to seizure load & $200 \mathrm{~N}$ to $400 \mathrm{~N}$ \\
\hline Speed & $90 \mathrm{rpm}[30 \mathrm{~mm} / \mathrm{s}]$ & $20 \mathrm{~Hz}[40 \mathrm{~mm} / \mathrm{s}]$ \\
\hline Temperature & Ambient & $80^{\circ} \mathrm{C}$ \\
\hline Duration & - & each $15 \mathrm{~min}$. \\
\hline Evaluation & Seizure load & $\begin{array}{c}\text { Friction } \\
\text { coefficient }\end{array}$ \\
\hline
\end{tabular}

Table 5 Test conditions of BOD tester

\begin{tabular}{|l|l|}
\hline Specimen & $\begin{array}{l}\text { Ball, SUJ-2 } \\
\text { Disk, SUJ-2 }\end{array}$ \\
\hline Load & $21.5 \mathrm{~N}$ \\
\hline Speed & $0.25 \mathrm{~Hz}[10 \mathrm{~mm} / \mathrm{s}]$ \\
\hline Temperature & Ambient \\
\hline Duration & 15 min. \\
\hline Evaluation & Friction coefficient \\
\hline
\end{tabular}

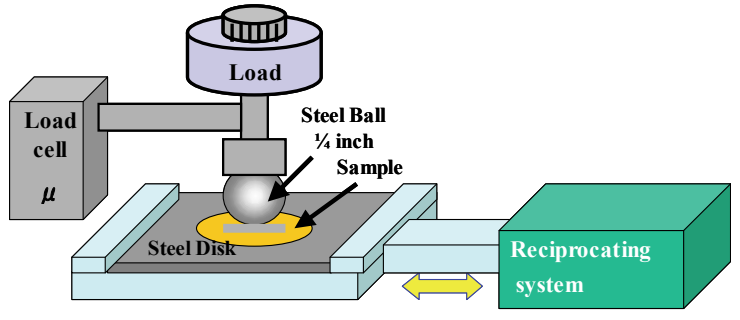

Fig. 5 BOD reciprocating sliding tester

\section{Results}

\subsection{Tribological tests}

Using pin on block FALEX tester, EP properties were examined. Fig. 6 shows seizure loads of TR Gel-Lube and lithium grease and solid lubricants containing samples. $\mathrm{MoS}_{2}$ and BN enhanced EP property of TR Gel-Lube. On the other hand, MCA and $\mathrm{ZnO}$ showed no effects. The same tendency was observed with lithium greases, however TR Gel-Lubes showed totally higher EP properties than lithium greases.

Using ball on disk SRV tester and BOD tester, friction properties were examined. Figs. 7 and 8 show friction coefficients of TR Gel-lubes on SRV and BOD tester, respectively. From SRV test results, it was observed that all type of solid lubricants reduced friction coefficient of TR Gel-lube. Especially, MCA showed good lubricity. On the other hand, sliding speed of BOD tester is very low compared with SRV. Solid lubricants showed no/low contributions to friction coefficient. It is suggested that oiliness effect of gel agent is quite high and solid lubricants might lower that effect. Nevertheless, MCA also showed lower friction coefficient in this condition.

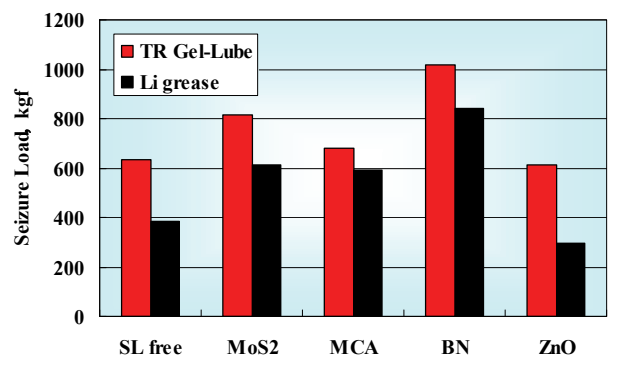

Fig. 6 Seizure load by pin/block FALEX tester

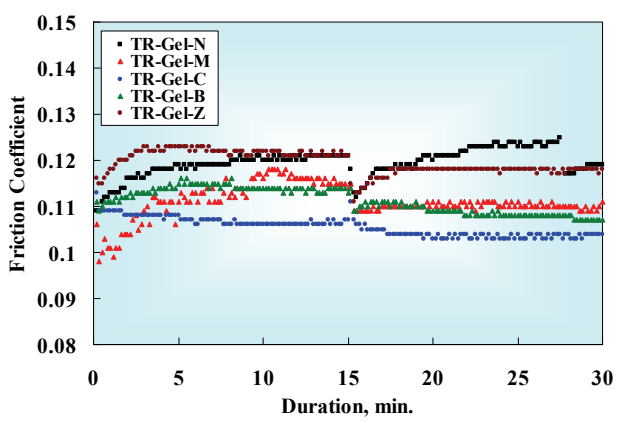

Fig. 7 Friction coefficient by ball/disk SRV tester 


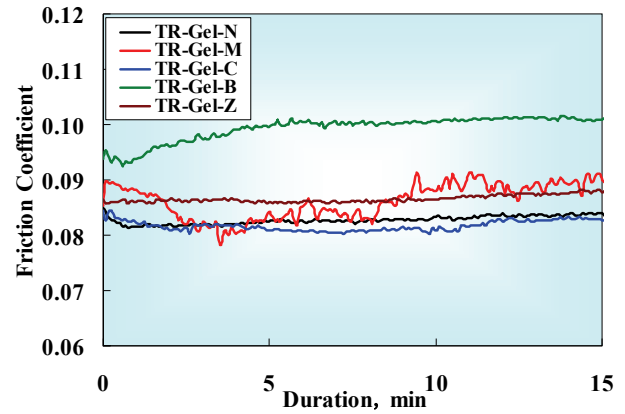

Fig. 8 Friction coefficient by ball/disk BOD tester

\subsection{Thermo gravimetric analysis}

Considering effects of solid lubricants to TR Gel-Lubes, aspects of thermal stability of solid lubricants were investigated. Fig. 9 showed reductions of weight of TR Gel-Lubes by TG, heating under atmospheric air. MCA containing sample is similar to solid lubricants free sample. $\mathrm{MoS}_{2}$ remained up to $400{ }^{\circ} \mathrm{C}$ and vaporized in $800{ }^{\circ} \mathrm{C}$ completely. $\mathrm{BN}$ and $\mathrm{ZnO}$ remained up to $1000^{\circ} \mathrm{C}$. High thermal stability of $\mathrm{MoS}_{2}$ and $\mathrm{BN}$ results in improvement of EP properties of TR Gel-Lubes.

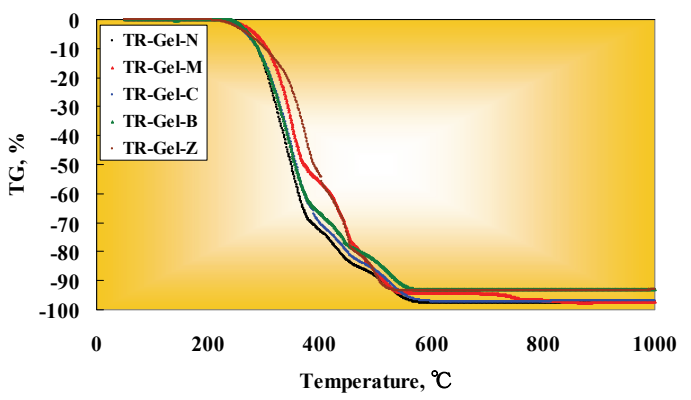

Fig. 9 Weight reduction of TR Gel-Lubes by TG

\subsection{Analysis of rubbed friction surfaces}

Influences of solid lubricants on actual friction surfaces were investigated by surface analyses. EPMA analyses were conducted of SRV specimens wear scars after friction tests. Table 6 showed surface elements. Upper values are presence ratio of elements atom\%. (Lower values) are normalized ratio compared with solid lubricants free sample (TR-Gel-N). Phosphorus was detected due to containing anti-wear additive, TCP. From $\mathrm{MoS}_{2}$ containing sample, Molybdenum and Sulfur were detected. From $\mathrm{ZnO}$ containing sample, Zinc was detected. However, information about MCA and BN was not obtained because of sensitivity.

To obtain more chemical information of $\mathrm{BN}$ containing sample, FT-IR micro spectroscopy analysis was conducted as shown in Fig. 10. Compared with non-rubbed surface, around $1000 \mathrm{~cm}^{-1}$ and $1400 \mathrm{~cm}^{-1}$ broad absorptions were observed on the wear scar. 1000 $\mathrm{cm}^{-1}$ absorption can be attributed to iron phosphate by tribochemical reaction between TCP and iron. $1400 \mathrm{~cm}^{-1}$ might be attributed to Boron oxide $\left(\mathrm{B}_{2} \mathrm{O}_{3}\right)$. In addition, the presence of $\mathrm{BN}$ itself was not observed by Raman spectroscopy, so BN might react to form boron oxide on friction surface.

Table 6 Surface element analysis by EPMA

\begin{tabular}{c|c|c|c|c|c|c}
\hline & $\mathrm{C}$ & $\mathrm{O}$ & $\mathrm{P}$ & $\mathrm{Mo}$ & $\mathrm{Zn}$ & $\mathrm{S}$ \\
\hline TR & 2.35 & 11.35 & 1.05 & - & - & - \\
Gel-N & $(1.0)$ & $(1.0)$ & $(1.0)$ & & & \\
\hline TR & 4.87 & 1.84 & 0.51 & 1.82 & - & 1.64 \\
Gel-M & $(2.07)$ & $(0.16)$ & $(0.49)$ & & & \\
\hline TR & 5.45 & 4.95 & 0.56 & - & - & - \\
Gel-C & $(2.31)$ & $(0.44)$ & $(0.53)$ & & & \\
\hline TR & 6.72 & 3.47 & 0.24 & - & - & - \\
Gel-B & $(2.85)$ & $(0.31)$ & $(0.23)$ & & & \\
\hline TR & 6.75 & 8.57 & 1.38 & - & 2.18 & - \\
Gel-Z & $(2.87)$ & $(0.76)$ & $(1.31)$ & & & \\
\hline Blanc & 6.50 & 1.97 & - & - & - & - \\
\hline
\end{tabular}

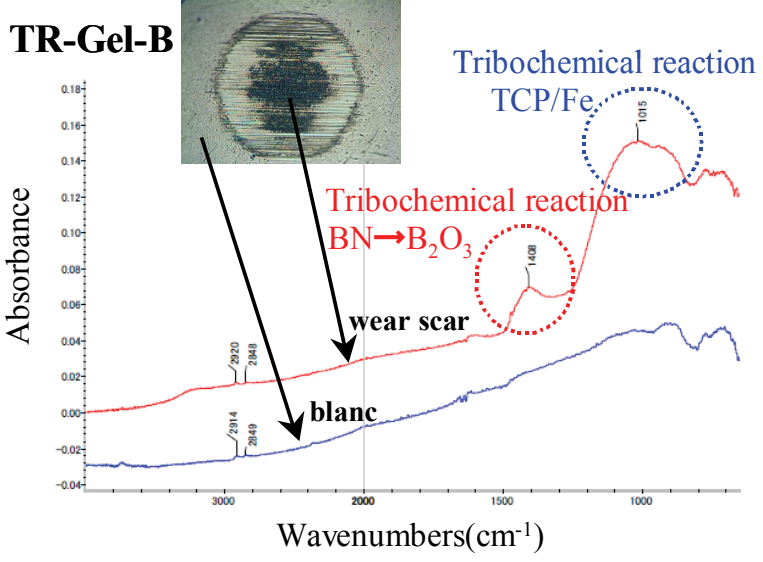

Fig. 10 FT-IR microspectroscopic spectra of SRV wear scar

\section{Discussion}

Considering these tribological properties and analyses results, mechanisms of TR Gel-Lubes and solid lubricants are proposed below.

Fig. 11 shows an image of friction surface when TR-Gel-M is used for lubricant. Gel agent adsorbs on metal surface like oiliness agent. $\mathrm{MoS}_{2}$ particles are sheared and show higher EP property under high-speed lubricating conditions. However, under low speed and light load lubricating conditions, $\mathrm{MoS}_{2}$ particles can't be sheared and might cause unstable friction coefficient.

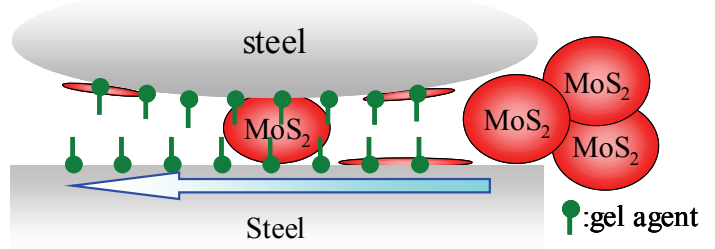

Fig. 11 Image of friction surface $\left(\mathrm{MoS}_{2}\right)$ 
MCA particles are smaller than $\mathrm{MoS}_{2}$ and easily introduced friction surface as shown in Fig. 12. Moreover, MCA has hydrogen bonds between melamine and cyanuric acid. The hydrogen bonds are formed to gel agent and the adsorbability of gel agent might be enhanced by concerted adsorption of melamine and cyanuric acid. As a result, oiliness effect of gel agent might be enhanced and low friction coefficient was observed.

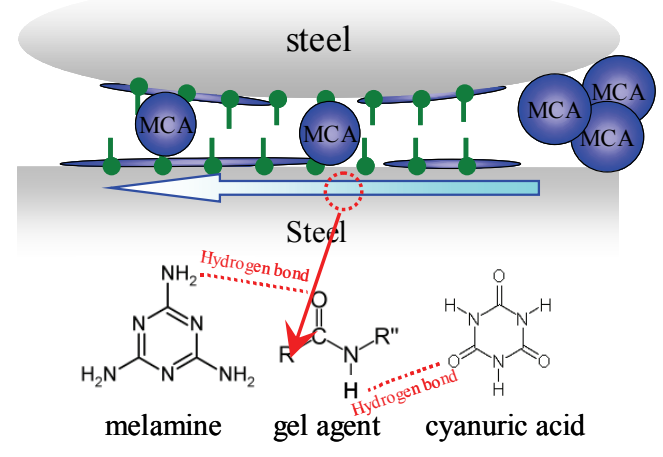

Fig. 12 Image of friction surface (MCA)

As shown in Fig. 13, the mechanism of BN might be similar to that of $\mathrm{MoS}_{2}$. Since $\mathrm{BN}$ has higher thermal stability, BN showed quite high EP property. By surface analyses, it is suggested that $\mathrm{BN}$ react to form $\mathrm{BO}_{\mathrm{x}}$. Kimura et al. reported that $\mathrm{BN}$ containing lubricating oil was applied for steel/steel or steel/iron sliding test and wear scars were analyzed by EPMA and XPS ${ }^{10)}$. BN showed anti-wear improvement and $\mathrm{BN}$ and new boron oxides species were detected on friction surfaces. Therefore, it is possible that the similar boron oxides species form by tribochemical reaction in the case of TR Gel-Lubes.

On the other hand, as shown in Fig. 14 nano-sized $\mathrm{ZnO}$ is too small to work efficiently, so $\mathrm{ZnO}$ showed no effect to EP and low friction properties.

\section{Summary}

The addition of solid lubricants was investigated to improve EP property of TR Gel-Lube. Tribological tests and analyses were conducted. The results are summarized below.

- $\mathrm{MoS}_{2}$ enhanced EP property and showed relative high thermal stability.

- MCA showed low friction coefficient.

- BN showed remarkable enhancement of EP property and higher thermal stability.

- $\mathrm{ZnO}$ showed no effect to EP and friction properties. Mechanisms of effects of solid lubricants to TR

Gel-lube were proposed. EP enhancements of $\mathrm{MoS}_{2}$ and $\mathrm{BN}$ resulted from cleavage property and high thermal stability. MCA interacted with gel agent through hydrogen bonds enhanced oiliness effect of TR Gel-Lube.

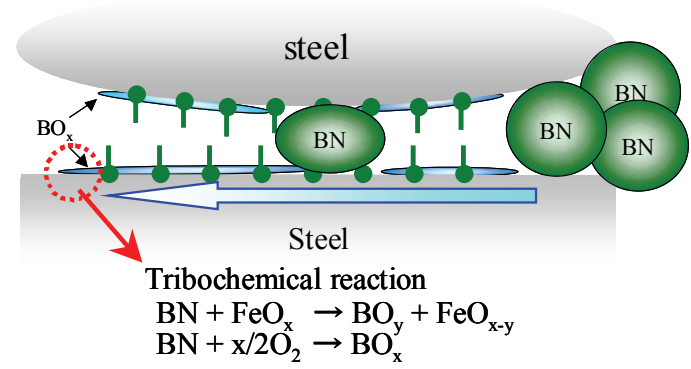

Fig. 13 Image of friction surface (BN)

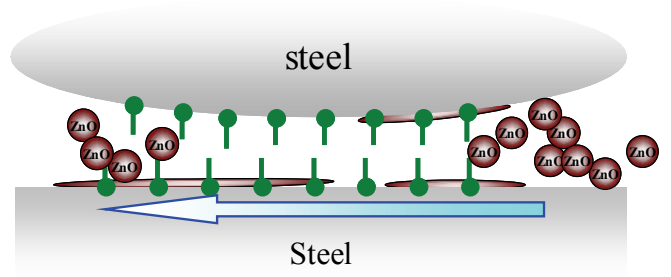

Fig. 14 Image of friction surface $(\mathrm{ZnO})$

\section{Acknowledge}

The authors wish to thank Prof. Mori, Iwate University for advices and discussion on mechanisms.

\section{References}

[1] Onuki, Y. and Kimura, H., "Applications and Research Trends of High Performance Synthetic Base Oils for Lubricating Greases," J. Japanese Society of Tribologists, 52, 4, 2007, 273-278. (in Japanese)

[2] Shitara, Y., Yoshida, K. and Kaimai, T., "Tribology of Thermo-Reversible Gel-Lubricants," Synopses of 34th Leeds-Lyon Symposium on Tribology, 2007.

[3] Takahashi, K., Shitara, Y. and Mori, S., "Direct Observation of Thermo-Reversible Gel-Lubricants in EHL by FT-IR Micro-Spectroscopy," Tribology Online, 3, 2, 2008, 131-136.

[4] Shitara, Y., Yoshida, K., Kaimai, T., Asari, M. and Takezaki, Y., "Tribology of Thermo-Reversible Gel-Lube," Proceedings of ASIATRIB 2006 Kanazawa, 1, 2006, 291-292.

[5] Risdon, T. J., "Molybdenum Disulfide in Greases a Review," NLGI, 69, 12, 2006, 14-18.

[6] Ballester, E., Manshi, S. and Fillon, C., "Effect of PTFE Particle Size on Wear and Coefficient of Friction," NLGI, 65, 6, 2001, 22-27.

[7] Kashiwaya, S., "Recent Application of Solid Lubricants for High-Load Conditions," The Tribology, 265, 2009, 24-26. (in Japanese)

[8] Rapoport, L., Leshchinsky, V., Volovik, Y., Lvovsky, M., Nepomnyashchy, O., Feldman, Y., 
Popovitz-Biro, R. and Tenne, R., "Modification of Contact Surfaces by Fullerene-Like Solid Lubricant Nanoparticles," Surface and Coatings Technology, 163-164, 2003, 405-412.

[9] Kobayashi, F., Enomoto, Y., Yamabe, T., Endo, M. and Fujinami, Y., "Synergy Effect of Vapor-Grown Carbon Nanofiber and Molybdenum Disulfide
Additives on Urea-Based Grease Thermal and Lubrication Properties," Tribology Online, 3, 4, 2008, 228-231.

[10] Kimura, Y., Wakabayashi, T., Okada, K., Wada, T. and Nishikawa, H., "Boron Nitride as a Lubricant Additive," Wear, 232, 1999, 199-206. 